Purdue University Purdue e-Pubs

1990

\title{
Hermetic Refrigerating Compressors and the CFC Substitution
}

\author{
E. Heinzelmann
}

Fmbraco

M. S. Ussyk

Fmbraco

Follow this and additional works at: https://docs.lib.purdue.edu/icec

Heinzelmann, E. and Ussyk, M. S., "Hermetic Refrigerating Compressors and the CFC Substitution" (1990). International Compressor Engineering Conference. Paper 744.

https://docs.lib.purdue.edu/icec/744

This document has been made available through Purdue e-Pubs, a service of the Purdue University Libraries. Please contact epubs@purdue.edu for additional information.

Complete proceedings may be acquired in print and on CD-ROM directly from the Ray W. Herrick Laboratories at https://engineering.purdue.edu/ Herrick/Events/orderlit.html 


\author{
ERNESTO HEINZELMANN
}

MARIO SERLIO USSYK

\author{
EMARACO - EMPRESA GRASILEIRA DE COMPRESSORES S/A
}

P.0.80X 027 - 89200 - JQINUILLE - SC - BRAZIL

\title{
ABSTRACT
}

The paper is divided into three parts. The first presents a basic eriterion for determining the most feasible substitute refrigerants for $[F C$ 12 in smal compressors. The method includes a simple analysis of some physical and thermodynamical properties of each refrigerant, within the ranges of evaporating and condensing temperatures where small refrigerating systems work. Parameters such as vapor pressure, compressian ratio, final isentropic compression temperature, volumic refrigeranc effect, and others permit a good relative comparison among the refrigerants.

The second part describes Embraco procedure for development of hermetic compressors adjusted to new refrigerants. project opinization, compatibility material analysis, performance and reliability product tests, and production means are considered. A time frame is established for the procedure, fram the preliminary refrigerant analysis through the production start-up.

In the last part, the strategy regarding the phase in of new environmental friendly refrigerants versus the phase dut of cF
compounds is dis compounds is discussad. Facus is given ta the differences among aeveloped countries and developing countries, where $\operatorname{lor}$, wil is useg
as an example.

\section{PRELIMINARY RNALYSIS OF THE REFRIGERANTS}

The following analysis must be seen only as a first step in tre search for, and determination of, a neurefrigerant to substitute CFE 12 in domestic refrigeration. This procedure is aimed at concepts are not in rom the point of vieu of the compressor. New revieu same of the parameters, trying only to bring together and have significant parameters presented in refrigeration books tnat hermetic compressors infunce on the performance of refrigerating only indicates favourable propad analysis is qualitative ano it apolication of neu rafrigerantend unfavourable aspects aoout the it permits some savings in as substitutes for. CFC 12 . However, investigation, expensive in time and expense by avoiding deep refrigerants that experiments and computer simulations of phase.

Obviausly, the refrigerants with high potential to substitute CFC 12 require extended investigations, and they certainly would not refrigerants some performance tendencies ars. However, for these 
simpitying the following stages of analysis.

It is impartant that the parameters not be considered at only one specific running condition, but over abl the operating range of the systems, since compressor performance is highby affected by the evaporating conoition. Therefore, the following parameters are plotted as a function of the evaporating range (-35 to $75^{\circ}[$ ), for a conscant candensing candition. The analysis may be enricned alsa by varying the candensing condition, althaugh this is not within tine scope of this work.

For example, the following comments referring to the comparisan of HEFL 22, HFC 134a and HFC 152a refrigerants with CFC 12 can be inage.

Figures 1 and 2 present a COP camparison among the different refrigerants under two distinct evaporating conditions. The first one, considers the refrigarant effeet without superheating, while the second one demonstrates this effect with superheating at $32^{\circ}$. In both cases, the initial compression vapor temperature is $32^{\circ}[$. The celative position of the refrigerants are distinst on both graphs at low evaporating temperatures. In the first graph, for example, HFC 152a is slightly above all the others uhile in the secand graph (with superheating) HCFC 22 is slightly below all the athers. Eased on these facts, we may say that the COP parameter is not sufficient for the qualification of a refrigerant, even in a preliminary analysis. Hermetic compressors are characterized by the high interaction of many simultaneaus phenomena. Suction gas superheating for instance, alters significantly the final performance of the compressor in such a way that small differences like the ones presented in the COP may be easily misunderstood. It is necessary to search for ather parameters for analysis.

Looking at the vapor pressure curve (figure 3 ), some differences may atready be seen. HCFC 22 has a vapor curve above CFE 12, while HFC T34a has a curve very elose to CFL 12 . HFE 152a has eurve constantly lower than EFC 12. Fram this figure we may has a eurve constanty lower than $134 a$ is the most appropriate substitute for EFC 12 .

However, based on the vapor pressure curve we may obtain a more detailed analysis using twa other oarameters of comparison: tre difference of compressor pressure between suction and discharge and the campression ratio.

The first parameter is represented in figure 4 . The pressure difference between the condensing and the evaporating temperatures has an impact on the bearing design and leakages in the compressar. Higher pressure difference requires strengthened gaskets, valves and other mechanical components, as well as bigger bearings.

Thicker walves as well as bigger bearings reduces compressor effieiency. The starting ability of the compressor during cyciling is also affected by higher pressure differences, requiring higher starbing tarque motors which mean less efficient motors.

In figure 4 we may observe that HCFC 22 is far above the others, including CFC 12. HFC 134a, although closer ta CFC 12 , is also above, which is not favourable.

Figure 5 presents the second parameter related to the vapar pressure curve. This is an extremely important parameter far the periormance of the compressor. It directly affacts the volumetric as well as the compession work. The lower the compresion ratios are, the oetter mechanical efficiencies we achieve. 
At higner evaporating bemperatures, all refrigerants tend to a common value. For louer evaporating temperatures, the refrigerants present significant differencas in compression ratios.

If we plot the compression ratio data from figure 5 relative to CFC 12 , uhich is done in. figure 6 , it is easy to notice that HFC lisa and especially HFC 134a have increasing values in relation to EFE 12, as evaporating temperature decraases. HFE 134a far example, has a compression ratio 308 higher than $C F E$ 12 at an evaporating temperature of -35० C. This indicates that the Derformance of HFE 134 a gets sensibly worse in systems that aperata. with lau evaparating temperatures.

From figure 6 we may also notice that HCFC 22 has a compression ratio very close to CFC 12 over the whole range.

Another characteristic uhich may be considered is the refrigerant temperature at the end af campression. Far small hermetic compressors we may assume an isentropic campression. Figure 7 indicates the final isentropic temperatures for the refrigerants in question.

The increase of the vapor temperature during compression is a iact with a considerable impact on compressor performance and reliability. High compression temoaratures cause oil degradation. valve cooking and carbonization. Besides that, it increases the heat transference potential in the compressor, tending to increase the temperatures of the suction vapor and the electrie motor.

Low evaporating temperatures, high condensing temperatures and gas superheating, increase the final vapar compression temperature.

Figure 7 shows that for high evaporating temperatures, the difference in the final compression temperature is smali. By decreasing the evaporating temperature, the difference between the refrigerants is well characterized.

HFC 134a has the best performance, just belaw CFC 12 . On the other hand, HCFC 22 and HFC 152a refrigerants have very high temperatures at the end of compression.

The next parameter to be considered is the specific refrigerating effect, understood as the specific enthalpy difference in the evaporator. It determines the mass flow to produce a desired refrigeration capacity. The higher the specific refrigerating
effect, the lower the mass flow must be.

The specific refrigerating effect varies drastically with the Liquid subcooling and vapor superheating temperatures and not that much uith the evaporating temperature. Ás may be seen in figure g, another.

All the refrigerants here analyzed, have sperific refrigerating effects larger than CFC 12. This can be interpreted as meaning that to obtain the same refrigerating capacity, the refrigerating systems Hill operate with lower mass flou. In the extreme $152 a s e$, for CFC 12.

Such significant variations imply major redesign of the valve system as webl as the compressor mufflers to adapt them to the very
low mass flows.

$$
\text { Finally, the }
$$


vobumic refrigerating effect as cited in reference ( 1 ).

The volumic refrigerating effect is the specific refrigerating efiect divided ay the specific vapor valume under a suction condition. It determines the compressor displacement necessary to produce a certain refrigarsting capacity. The higher the volumic refrigerating effect, the laver khe compressor displacement must be.

Figure 9 shows that the curve for HCFC 22 is higher than the group of other reftigerant curves, including CFE 12 . When the volumic refrigerating effect is platted in relation ta $[F[12$, as in figure 10, ve observe that to keep the same refrigerating capacity, a compressor which operates with HEFE 22 must have a displacement close to half of that of a compressor operating with [FC 12. This is an enormous uarier to use of HCFE 22, since domestic refrigerating compressors already have a smal displacement and it vould be practically impossible to reduce them to that level.

On the other hand, HFC 152a would require a displacement approximately 10\% larger than CFC 12 which is easier to obtain. It is interesting to notice that the behaviour of HFC 134a crosses the EFE 12 curve. Again, this indicates the inferior performance of HFC 134a for law evaporating temperatures. Far example, roughly saying, if the displacement of the compressor is calculated for the same capacity as [FC 12 at an evaporating temperature of $-10^{\circ} \mathrm{C}$, the compressor will have appraximately $10 \%$ less capacity with HFC 134a when operating at $-35^{\circ} \mathrm{C}$.

From what has been presented abave, we may affirm that HCFC 22 o chance to replace CFC 12 for domestic refrigerating applications with low evaporating temperatures. The volumic refrigerating effect curve demonstrates that it is practicabby impossible to adapt small compressors to the use of HCFC 22 . At the same time, the curves of pressure difference between suction and discharge, as well as the final compression temperature, also play a very unfavourable role.

Concerning the other refrigerants, HFC $134 \mathrm{a}$ and HFC 152a, it was not possible to obtain expressive arguments which cauld lead to the elimination of any of these candidates. Although some further comments can be made.

HFC 134a snowed deficiencies at tow evaporating temperatures. The high compression ratio is the main negative factor. Higher pressure difference betveen suction and discharge and the tendency of the volumic refrigerating effect curve, may also contribute negatively. As a positive aspect, the low temperature at the end of compression may be mentioned.

HFC 152a does not have such apparent disadvantages as HFC 134a for Low evaporating temperatures, On the other hand, the reduced mass flow certainly will demand changes in the campressar, as well as the high discharge temperature, uhich acts negatively far this refrigerant.

\section{DEVELOPMENT OF COMPRESSURS APPLICABLE TO NEW REFRIGERANTS}

For many decades domestic refrigeration has been working with CFE 12 as a refrigerabing fluid. There were no doubts about the advantages of this product, so that it is now used by all of the manufacturers.

In this case, substitution can not be seen as a simple change from CFE 12 to another refrigerant, keeping the same design and immediately obtaining favourable results. 
The imoack of this change is enarmous. Several feacures must be considerea cogetner: energy consumption, comfort (noise), safety (toxicitylfbammadilicy), avaibaoibity, adjustment to gxisting products, and, ooviously, environmental aggressiveness level coDP, GWP). Besides these, the cost parameter can not be neglected, specially in developing countries.

Up to the moment, there is no final decision on the $C F C$ 12 substitute for damestic and small comercial refrigeration. On the other hand, the CFC 12 phase out pressures have increased considarably.

Based an the above, Emoraco was compelled ta establish a very $f$ lexible compressor development program applicable to new refrigerants.

Each refrigerant that appears as a probable CFC 12 substitute iniciates a route, such as the one indicated in figure 11 . The program has some decision steps where the results af each concluded stage are analyzed and the decisian on the continuity ar not of the refrigerant in the develapment pragram is taken.

The first ster, "Refrigerant Preliminary Analysis", is nothing mare than what was presented in the first part of this paper. It is a quick task, where only some knowledge of the physical and thermadynamical properties of the refrigerant are required. Once the refrigerant is approved, it proceeds to the thicd step.

Step 3, "Initial Experimental Analysis", begins vith the availability of refrigerant and oil samples. Analysis of solubility and miscibility of the refrigerantloil mixture is made. Compatibility tests of materials with the ney refrigerant and ail, are started, also. First, life and vear tests are also carriec out. Compressar performance in calorimeter and noise tests, 5 tarting ability and stalling is evaluated. Experiments such as the aquisition of the PxV diagram, valve motions and the compressor thermal profile are important data to be analysed. When this step is concluded, it is possible to have a very precise idea of the impact caused by the new refrigerant in the actual compressors designed for
CFC 12.

It is time nou to proceed to the second and important decision. Does the refrigerant being analysed really have passibilities to replace [FC 12 with same advantages? Only the refrigerants uith nign patential snould proceed from this point.

When the refrigerant is approved in decision step 4 , it is time ta begin the "Prototype Definition". Product requirements are established. The compressor must be redesigned according to simulation programs and experiments. Tests are made with oifferent pratotype configurations. Manufacturing feasibility analysis and prototype campressor companents design are dane.

In sequence, step 6 - "Pratatype Tests", Lats are manufactured ta check the reliability, performance and ip months, appraximately. The time estimated for 5 teps 5 and 6 is

In step 7, it is time to decide on the manufacturing of compressars according to the nev refrigerant. Having reachea af positive decision, the "Product Develapment" - step 8 - is

The product development step consists in final product design, supplier development and produetion faeilities adjustments. 
Finally, step 9 covers the starting of pilot production up to normal production. Steps 8 and $g$ should last at bast 12 months.

The averall time estimated for the comolete develooment program is from 24 to 99 mantis.

Nevertheless, it cannat be fargatten that the chaice of a new refrigerant is not an individual decision. Compressor manufacturers, refrigeration appliance producers, refigerant manufacturers and govermments play a very important role in this scenario. The overabl time expectancy depends on how quickby and how preciseby the decisions are made.

\section{CFE REPLACEMENT IN DEVELOPING COUNTRIES}

In developed countries the consumption of CFC's is distributed over many different applications. These applications were developed for different reasons. normalby linked to comfort parameters (like Car A.C. aerasols, home insubation, etc,), or ta processing technologies (food processing. cleaning processes, tobacca puffing. etc.). Because of the cost associated with such applications, or due to the lack of available technology, many of these applications are used an a very small scale or not at all in developing countries. In fact, the use of CFC's in developing countiles is normalty directed to basic applications, such as the refrigeration industry. We may mention some examples, using Brazil as a reference for a develaping country.

- The total CFC consumption in Brazil is around 10,000 ton/year, unich represents less than 13 of the world consumption. Assuming a papulatian of 150 million inhabitants, Brazilian consumption reaches 0.07kg CFClinhabitants year.

In comparison, the U.S.A., where CFC consumption is appraximately 300.000 tonlyear - roughly $1 / 4$ af the worlo total consumption, per capita consumption is 18 times the Brazilian one, reaching $1.25 k g$ CFClinhabitant year assuming the U.5. pooulation as 240 milbions.

- In the U.S.A. approximately $20 \%$ of CFE consumption is used in autamobile air conditioners. In Brazil, despite its tropical climate, this applicabion represents less than $5 \%$ of $\theta r a z i b i a n ~ C F C$ consumption.

- In Western Europe, 40\% af CFC cansumption is used far aerosobs, This application was never representative in Brazil and the use is cestricter to essential medicinal application since 1988.

- In Brazil, CFC consumption for domestic refrigeration and 5 mal commercial units, which use CFC 72 in the system and CFL 11 for foaming, is approximately $25 \%$ of total annual CFE consumption. Considering the developed countries, this figure is nat higher than $5 \mathbf{z}$.

- 70x of the Brazilian home refrigeration market is concentrated in ane-door refrigerators with an interial volume up to 290 litgrs. 5mal and simple refrigerators nave the advantage of using smaller quantities of CFE's and louer power consumption. Many of the onedoor refrigerators produced in Brazil are able to meet the 1990 U.S. DOE standards.

- Finably, the increase in the product casts uhich wil occur through the use of alternative refrigerants may reduce many people's ability to buy their first refrigeratar, in a market which is far from saturation.

The Montreal Protocal recagnized this situation by allowing the countries with a consumption of less than 0.3kg per capita to enforce the established restrietions within 10 years ar upon reaching the limit of $0.3 \mathrm{~kg}$ per capita, whichever occurs first. Such 
protection snould oe kapt in the revisian of the protocol to alow for the time necessary to absorb the new technologies involved uitn [FC replacement, particularly in view of the small contribution to ozone depletion caused by developing countries.

Up to now there is no clear deitinition of which refrigerants will replace the ones now being used for domestic refrigeration. It may be that in Europe, far instance, HFC $134 a$ vilh replace CFE 12 while in the U.S.A., due to the energy consumption penalty being reported, probably another refrigerant will be adopted.

Developing coutries, with low financial and technical resources, and a smalt countribution to the ozane depletion problem, should be allowed the chance and time to adapt their internal market to the best alternative, already proven in developed countries. The developed cauntries should supodrt the developing cauntries in applying the required technolagy. This is absa being considered in the Montreal Protocol and will certainly help ta phase out cF usage worldwide. This support should not be restricted ta just financing industrial projects, which may be successful or not, but ta promoting the effective transfer of know why.

Brazilian production of hermetic compressors for refrigerators and freezers in 1989 was over $11 \mathrm{million} u n i t s$. Approximately Gog of this volume was directed to the external manket. Exports of refigerators and freezers are also increasing year by year. Mast of these exports are to developed countries, which have very strong programs for replacement of CFC's in the 1993-1998 time frame. In some cases, mainly in the U.S.A., besides the restriction on using CFC's, stricter energy standards are alraady defined. For Brazil, this situation can be considered as a driving force to develop the bechnology for using new refrigerants in the same time frame as the developed countries.

The compressar and refrigeration industries have long recognized the necessity of following international targets. Embraca has nearly 8 of of the world market in hermetic compressors for refrigeration, with exports cancentrated in large volumes to the U.5.A. and Europe. We certainly have to follow international trends and we ara sure that we ean be successful.

\section{REFERENEE}

1. Gosney, W. B. - Principles of Refrigeration,

Cambridge University Press 1982، 178.

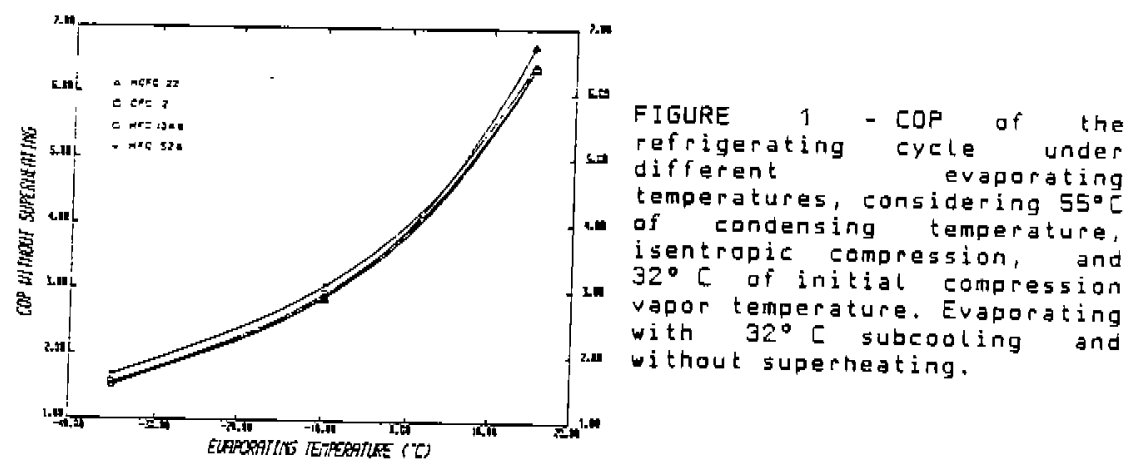


FI UURE 2 - COP of the refrigerating cycle under different evaporating cemperatures, considering $55^{\circ} \mathrm{C}$ of condensing temperature, isentropic compression, and 32 'C of initial compression vapar temperature. Evaporating with $32^{\circ}\left[\right.$ subcaoling, and $32^{\circ}[$ superheating.
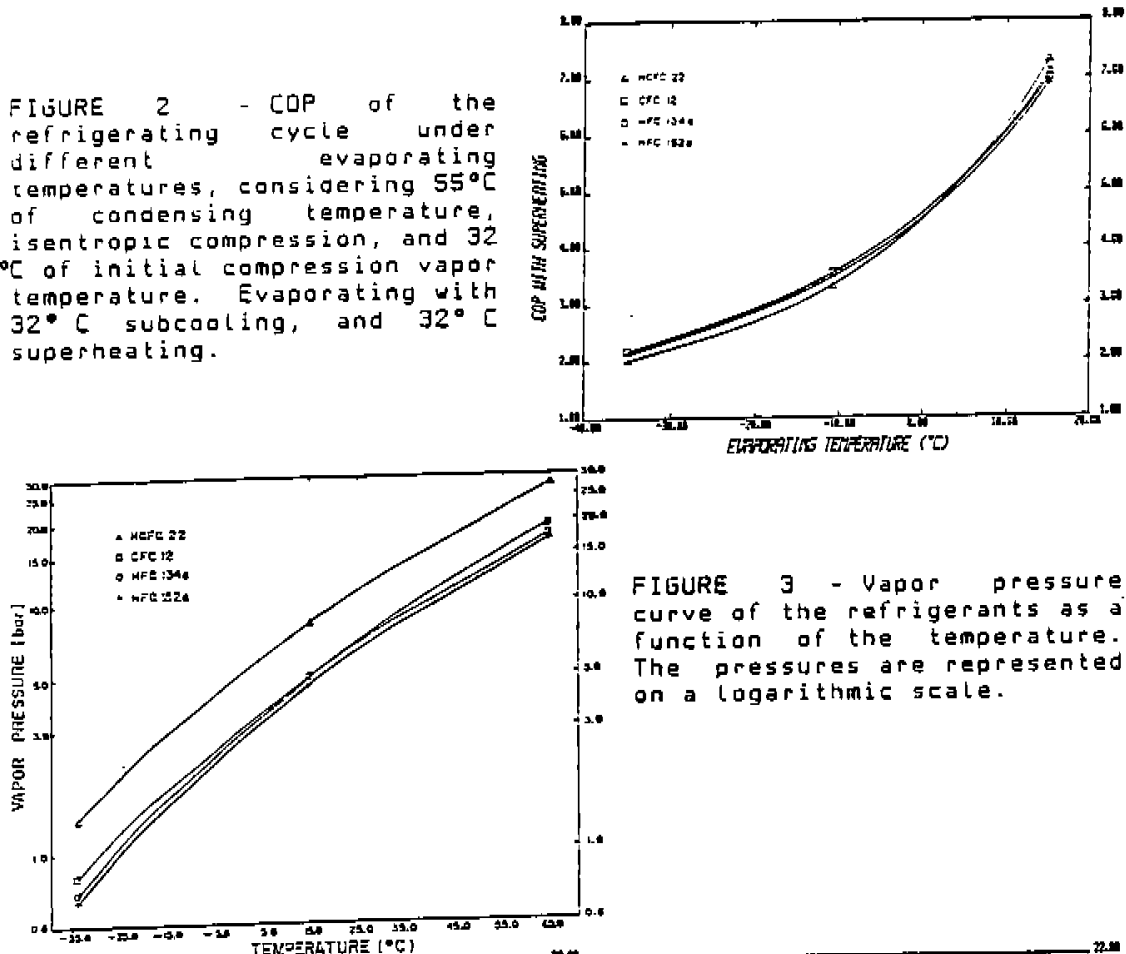

FIGURE 3 - Vapor pressure curve of the refrigerants as a function of the temperature. The pressures are represented on a logarithmie scale.

FIGURE 4 - Pressure difference between compressar suction and discharge at $55^{\circ}$ C condensing temperabure.
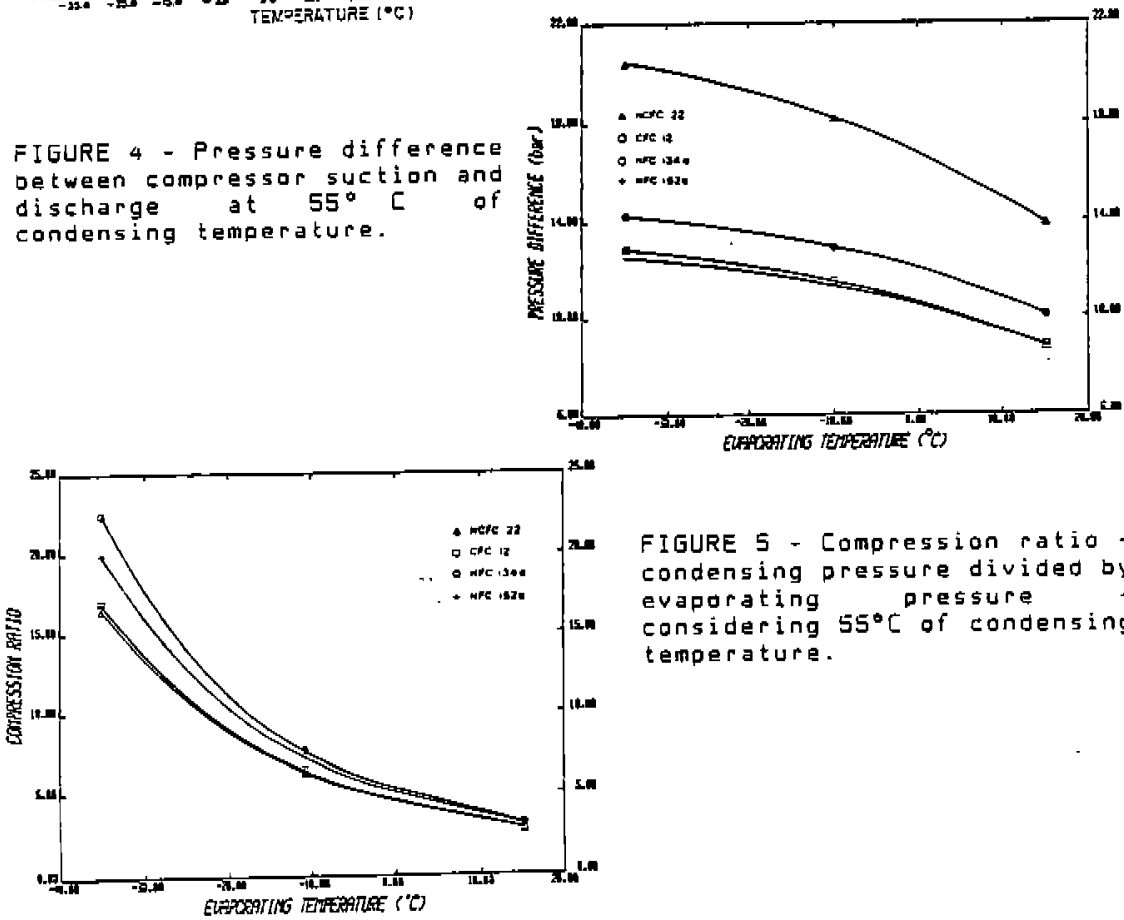

FIGURE 5 - Compression ratio condensing pressure divided by evaporating pressure considering $55^{\circ} \mathrm{C}$ of condensing temperature. 
FI GURE 6 - Eompression ratio ca different refrigerants relative to the EFC 12 (CFE 12 is used as refergnce over the evaporating range).
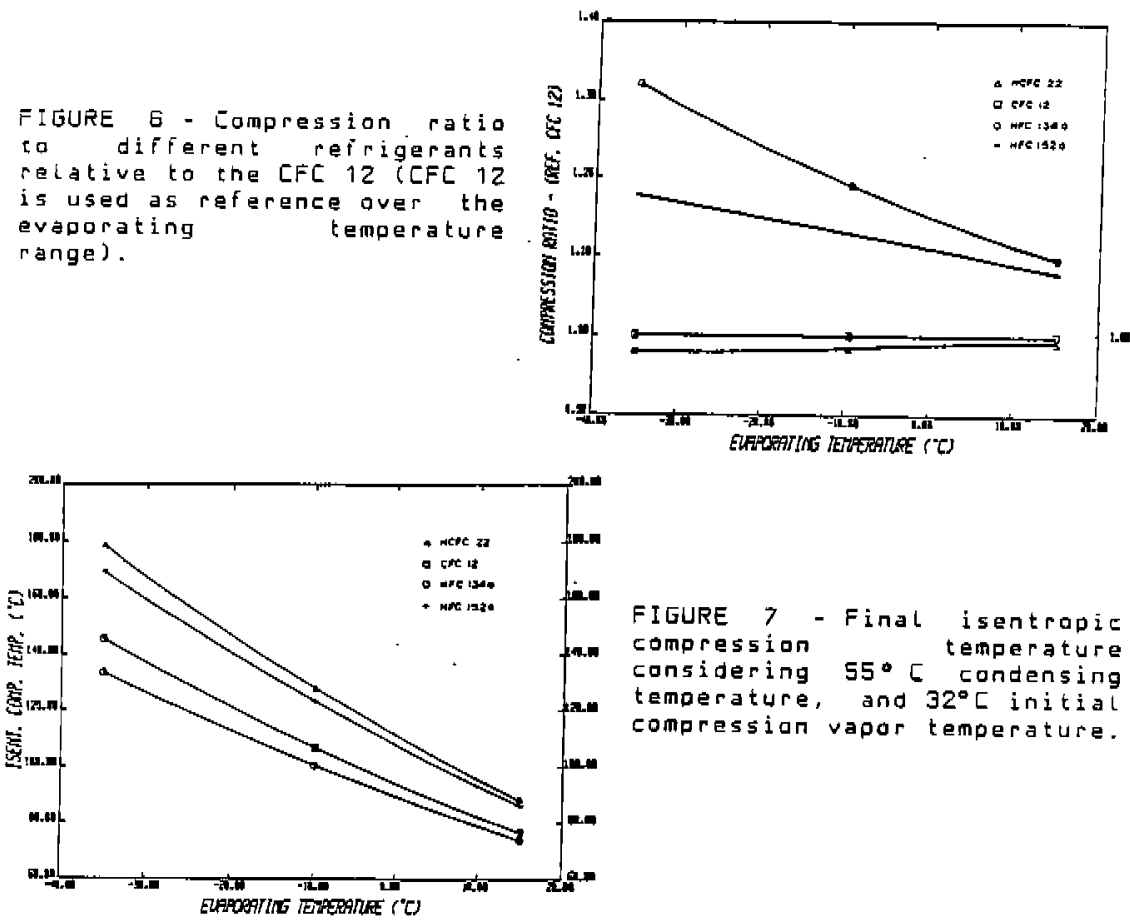

FIGURE 7 - Final isentropic compressian temperature considering 55* 5 condensing temoerature, and $32^{\circ}[$ initial compressian vapor temperature.

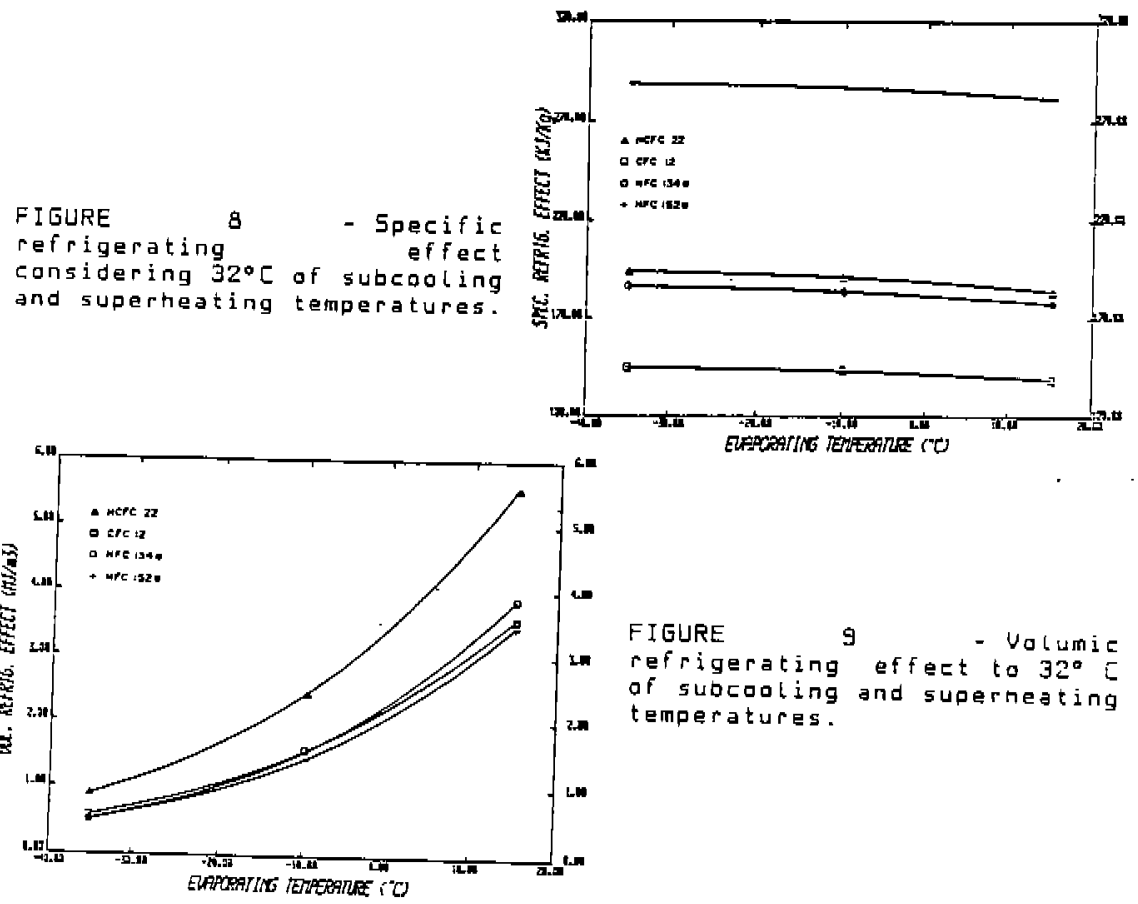



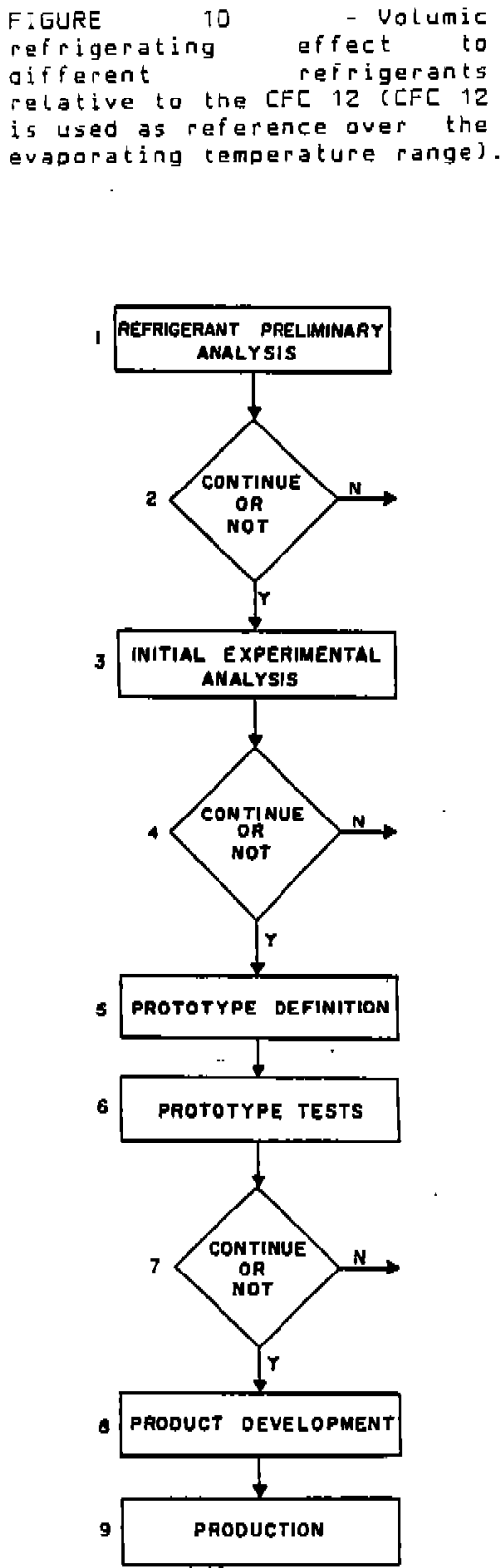

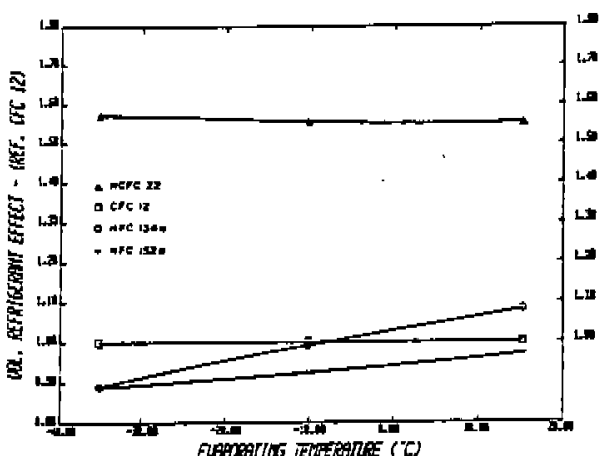

FIGURE 11 - Block diagram to tine compressor development program applicable ta new refrigerants. 